\title{
CORRESPONDENCE
}

\section{The European Community Respiratory Health Survey II}

\section{To the Editor:}

The European Community Respiratory Health Survey (ECRHS) II is a multicentre study that includes assessment of bronchial responsiveness using the Mefar ${ }^{\mathrm{TM}}$ dosimeter (Mefar $^{\text {TM }}$, Brescia, Italy). WARD et al. [1] report that in some centres taking part in ECRHS II, there is potential for systematic variation in Mefar ${ }^{\mathrm{TM}}$ dosimeter driving pressure, which constitutes possible significant confounding for between-centre comparisons of bronchial hyperresponsiveness. They reported a wide range of driving pressures between centres "ranging between $70-245 \mathrm{kPa}$, with most outside the quoted manufacturer's specification of $180 \pm 5 \% "$.

WARD et al. [2] drew our attention to this problem when we were developing the quality control programme for ECRHS II. All ECRHS II centres were requested to check dosimeter driving pressure at least once a month and to send reports to the Coordinating Centre. Where readings were $<160 \mathrm{kPa}$ or $>180 \mathrm{kPa}$, centres were advised to adjust the dosimeter to a level within these limits. R.J. Ward and his group set up a website with instructions on how this could be achieved, together with information on the testing procedure.

Reports were received from all centres except for Umea (Sweden) and showed that no centre recorded a level $<160 \mathrm{kPa}$ and the highest value was $200 \mathrm{kPa}$, found in Hamburg (Germany). In Hamburg, alterations were made to the equipment and it operated at $\sim 180 \mathrm{kPa}$ for the rest of the study. The mean pressure for centres throughout the study ranged $160 \mathrm{kPa}-189 \mathrm{kPa}$ (Hamburg had a higher mean due to its driving pressure being $200 \mathrm{kPa}$ for a period).

Although table 1 of the paper concerned [1] implies a substantial problem within the participating European Community Respiratory Health Survey II centres, the quality control programme reveals that although variation exists, the magnitude and its influence on between-centre comparisons is much smaller than suggested by WARD et al. [1] in their recent paper.

J. Knox, D. Jarvis, on behalf of the ECRHS II Steering Committee

Dept of Public Health Sciences, King's College London, London, UK.

\section{References}

1. Ward RJ, Ward C, Johns DP, Skoric B, Abramson M, Walters EH. European Community Respiratory Health
Survey calibration project of dosimeter driving pressures. Eur Respir J 2002; 19: 252-256.

2. Ward RJ, Liakakos P, Leonard RF, Reid DW, Johns DP, Walters EH. A critical evaluation of the Mefar ${ }^{\mathrm{TM}}$ dosimeter. Eur Respir J 1999; 14: 430-434.

\section{From the authors:}

The letter from J. Knox and D. Jarvis about the outcome of the dosimeter quality control programme for the measurement of bronchial hyperresponsiveness in the European Community Respiratory Health Survey (ECRHS) II is reassuring. Although our initial worries about excessive variation between Mefar $^{\mathrm{TM}}$ dosimeter $\left(\mathrm{Mefar}^{\mathrm{TM}}\right.$, Brescia, Italy) driving pressures from our own observations [1, 2] do not seem to have been confirmed in most of the ECRHS centres, the value of the quality control programme does seem to have been validated.

Although the variations in driving pressures reported to the Coordinating Centre were not as great as we had observed with a number of dosimeters from a small number of international centres, the range of mean pressures quoted still seems to be outside the manufacturer's specifications of $180( \pm 5 \%) \mathrm{kPa}$. We made a proposal to the ECHRS II for our laboratory to act as a "neutral" and a confidence reference agency to collect and collate the calibration information obtained by study centres following the instructions we provided on our website. For the sake of complete objectivity, it is perhaps a pity that this did not occur. Even so, we are pleased that our work to highlight a potential difficulty with the Mefar ${ }^{\text {TM }}$ dosimeter has been very worthwhile, and will certainly have even greater confidence in the data generated by ECHRS II.

\section{E.H. Walters}

University of Tasmania, Hobart, Tasmania, Australia.

\section{References}

1. Ward RJ, Ward C, Johns DP, Skoric B, Abramson M, Walters EH. European Community Respiratory Health Survey calibration project of dosimeter driving pressures. Eur Respir J 2002; 19: 252-256.

2. Ward RJ, Liakakos P, Leonard RF, Reid DW, Johns DP, Walters EH. A critical evaluation of the Mefar ${ }^{\mathrm{TM}}$ dosimeter. Eur Respir J 1999; 14: 430-434.

\section{Chronic obstructive pulmonary disease: underdiagnosed, underinvestigated, inappropriately managed?}

\section{To the Editor:}

The article of RENNARD et al. [1] and the accompanying editorial by DEKHUIJZEN [2] proposed that chronic obstructive pulmonary disease (COPD) is not only underdiagnosed and underinvestigated but also that the morbidity is underestimated. The evidence on which they base this hypothesis lacks two essential components. These are independent assessments of exercise tolerance and objective measurement of lung function. If disability is primarily to be attributed 
to COPD then it must be associated with a commensurate physiological abnormality, which is a reduction in afterbronchodilator forced expiratory volume in one second (FEV1) or at least abnormality of the flow/volume loop. In medicolegal practice, I have been seeing large numbers of subjects managed principally in general practice with COPD or symptoms wrongly attributed to it. Too frequently, limitation of exercise cannot be explained by the objective reduction in pulmonary function. My previous clinical practice leads me to believe that this is not confined to any particular group of patients and certainly not related to litigation. The vast majority of patients have access to appropriate medication and use it in at least the prescribed dose, so there is little room for improvement in the pharmaceutical approach. Nevertheless there is much perceived and real morbidity. The tragedy is that much of the associated disability is not only accepted too passively, but is also unnecessary.

The diagnosis may be made on the basis of no pulmonary function tests or tests of poor quality. Often, the mere presence of cough and sputum or an industrial history leads to the diagnosis, which is then indelibly reproduced in the notes without thought as to its validity, even if subsequent pulmonary function tests are normal. Too often, a history of breathlessness is accepted at face value as objective evidence of disability due to respiratory disease. The perceived level of exercise limitation probably does reflect actual activity, but is rarely objectively confirmed either explicitly or opportunistically as, for example, by comparison with performance on the Bruce protocol. Overdiagnosis is only part of the problem. Many of these subjects do have mild COPD as demonstrated by minor changes in FEV1 or the shape of the flow/volume loop, but with disproportionate exercise limitation. The clinician accepts the diagnosis, maybe rightly, but attributes disability directly to it, usually wrongly.

The problem arises because breathlessness is incorrectly regarded as the prime symptom reflecting impairment associated with cardiorespiratory dysfunction. This, however, is not the case. It is exercise limitation itself that is the proper measure of cardiorespiratory dysfunction. If cardiorespiratory dysfunction is the direct cause of this exercise limitation then it must be associated with changes in carbon dioxide or acid-based balance causing fatigue or the legs to give out. This is well recognised in athletes who accept breathlessness as incidental. It should apply equally to those with COPD, particularly when the disease is mild. In practice it is the dislike of breathlessness itself and the consequent vicious circle of increasing perceived breathlessness, exercise restriction and muscle weakness that is the prime cause of disability in COPD and not the actual impairment of lung function. Whether or not the COPD itself contributes to the perception of breathlessness is immaterial.

Management must involve acceptance by the patient of the true cause of disability, a message often difficult to convey in these days of patient autonomy, followed by rehabilitation to reverse the vicious circle. The approach might include: 1) taking history, directed first at the extent of disability and then at the associated symptoms, with the least reliable, breathlessness, last in the list; 2) objective assessment of exercise tolerance in all cases; 3) an absolute requirement for a physiological confirmation of the diagnosis by spirometry, including flow/volume loops (most unhelpful in this respect is the concept of stage 0 COPD as cough and sputum; it should be normal FEV1 with abnormality of the flow/volume loop); 4) development of tables of optimal rather than average exercise tolerance against FEV1\% predicted, stratified by the shape of the flow/volume loop; and 5) immediate intervention with low-tech rehabilitation in primary care, with the triple benefit of preventing unnecessary morbidity, ensuring that those whose disease does subsequently decline are already in the best position to cope with it, and reducing the impact of COPD as comorbidity in other conditions.

By addressing the underlying problem of inability to cope with breathlessness, this physiological approach might substantially reduce the burden of COPD, which is indeed excessive, but not always for the reasons suggested by RENNARD et al. [1] and DeKHUIJZEN [2].

\section{C.K. Connolly}

Aldbrough House, Aldbrough St John, Yorkshire, UK.

\section{References}

1. Rennard S, Decramer M, Calverley PMA, et al. Impact of COPD in North America and Europe in 2000: subjects' perspective of Confronting COPD International Survey. Eur Respir J 2002; 20: 799-805.

2. Dekhuijzen PNR. The Confronting COPD International Survey: patients hardly know they have COPD. Eur Respir $J$ 2002; 20: 793-794.

\section{From the authors:}

We are pleased to respond to the comments made by C.K. Connolly. We completely agree with the need to dissociate disability from dyspnoea in the clinical assessment of the chronic obstructive pulmonary disease (COPD) patient. Dyspnoea can arise from many inputs, and, while it correlates with airflow limitation, it does so relatively poorly. Dyspnoea can limit performance. We agree with the suggestion that evaluation of exercise performance can assist in the evaluation of COPD patients. Muscle weakness, however, is a better predictor of disability in COPD than airflow, and this weakness may be due not only to detraining, but also to the inflammatory processes and circulating cytokines that characterise some COPD patients. Because of this latter point, we disagree with C.K. Connolly's suggestion that disability in COPD must be related to the measurable forced expiratory volume in one second (or flow/volume loop) abnormalities.

Clearly the chronic obstructive pulmonary disease patient's clinical status reflects not only the impaired airflow, but also other pulmonary and systemic aspects of the disease. We doubt the disease is underdiagnosed; our survey, in fact, focused on diagnosed cases. Among those individuals, we have little doubt that it is underevaluated. C.K. Connolly's suggestion that more aggressive assessment of objective measures in the chronic obstructive pulmonary disease patient is needed is one with which we wholeheartedly agree. More aggressive identification of the undiagnosed individuals will also be important.

\section{S.I. Rennard*, M. Decramer", P.M.A. Calverley", N.B. Pride ${ }^{+}$, J.B. Soriano ${ }^{\S}$, P.A. Vermeire ${ }^{f}$, J. Vestbo**} *Pulmonary and Critical Care Medicine Section, Dept of Internal Medicine, University of Nebraska Medical Center, Omaha, NE, USA. ${ }^{\#}$ Respiratory Division, Catholic University of Leuven, Leuven, Belgium. "University of Liverpool, Dept of Medicine, Clinical Sciences Centre, University Hospital Aintree, Liverpool, UK. ${ }^{+}$Thoracic Medicine, National Heart and Lung Institute, Imperial College School of Medicine, London, UK. ${ }^{\S}$ Worldwide Epidemiology, GlaxoSmithKline Research and Development, Greenford, UK. ${ }^{f}$ Dept of Respiratory Medicine, University of Antwerp, Antwerp, Belgium. ${ }^{* *}$ Dept of Respiratory Medicine, Hvidovre University Hospital, Copenhagen, Denmark. 